\title{
AGAINST MARINE RISK: MARGINS DETERMINATION OF OCEAN MARINE INSURANCE
}

Chien-Chung Nieh

Professor, Department of Marine Engineering, National Taiwan Ocean University, Keelung, Taiwan 202, R.O.C, niehcc@mail.tku.edu.tw

Yi-Lin Jiang

Ph.D. student, Graduate Institute of Banking \& Finance, Tamkang University, Tamsui, Taiwan 251, R.O.C.

Follow this and additional works at: https://jmstt.ntou.edu.tw/journal

Part of the Business Commons

\section{Recommended Citation}

Nieh, Chien-Chung and Jiang, Yi-Lin (2006) "AGAINST MARINE RISK: MARGINS DETERMINATION OF OCEAN MARINE INSURANCE," Journal of Marine Science and Technology. Vol. 14: Iss. 1, Article 2.

DOI: $10.51400 / 2709-6998.2075$

Available at: https://jmstt.ntou.edu.tw/journal/vol14/iss1/2

This Research Article is brought to you for free and open access by Journal of Marine Science and Technology. It has been accepted for inclusion in Journal of Marine Science and Technology by an authorized editor of Journal of Marine Science and Technology. 


\title{
AGAINST MARINE RISK: MARGINS DETERMINATION OF OCEAN MARINE INSURANCE
}

\author{
Chien-Chung Nieh* and Shi-Jie Jiang**
}

Key words: ocean marine insurance, underwriting margin, underwriting cycle, ARDL cointegration.

\begin{abstract}
As the origin of modern insurance, ocean marine insurance exhibits numerous distinctive characteristics compared with the rest of the property/casualty insurances. This paper originally investigates the determination of the underwriting margin of ocean marine insurance, which is the crucial component of the ocean marine insurance price. Focused on industry-wide level, earlier studies ignored the time series characteristics of underwriting margin to utilize conventional regression, or employed time series methods but were limited with the stationary property of variables. Consistent with prior empirical studies despite of whether considerable variables have unit roots, an ARDL approach for underwriting margins in U.S. ocean marine insurance market during the sample period: 1951-2001 demonstrates that the financial pricing hypothesis [3] is the most suitable model. Such results confirm several unique features of ocean marine insurance market and give reasonable explanation of underwriting cycle, which is a familiar fluctuations progress in marine insurance market.
\end{abstract}

\section{INTRODUCTION}

Ocean marine insurance is generally known as the first type of insurance in history. The oldest tangible evidence of this insurance is a policy written by Italian merchants in 1343. Lloyd's of London issued the first actual ocean marine insurance policies as we more or less know them today in 1688. The U.K. ultimately codified laws and regulations pertaining to ocean marine insurance through the Marine Insurance Act of 1906, which proved the biggest influence shaping international marine insurance laws since. Because ocean marine insurance was the first kind of insurance to take on a modern format, other kinds of insurance operations-particularly in property and liability insurance-

Paper Submitted 02/23/05, Accepted 05/06/05. Author for Correspondence: Chien-Chung Nieh.E-mail: niehcc@mail.tku.edu.tw.

*Director of the Department and Graduate Institute of Banking and Finance, Tamkang University, Tamsui, Taiwan 251, R.O.C.

**Ph.D. student, Graduate Institute of Banking \& Finance, Tamkang University, Tamsui, Taiwan 251, R.O.C. have been strongly influenced by it. Modern ocean marine insurance covers property damage and liability to both goods being shipped and the vessels containing them. It also comprises insurance on other waterborne exposures such as vessels and cargoes on inland waterways, as well as drilling rigs and other property used for the exploration, development, and production of offshore oil and natural gas deposits. The coverage can be divided, like other property/casualty areas, into commercial and personal lines. Commercial marine insurance consists of three types of coverages. Cargo policies, the largest segment, cover loss or damage to goods being shipped, while hull policies cover vessels shipping the goods. Protection and Indemnity (P\&I) policies cover liabilities between ship owners. Personal ocean marine policies have the same coverages, but pertain to yachts, pleasure crafts, motor boats and other boats not used commercially. In the United States, over nine-tenths of ocean marine premiums are written in commercial lines.

As the root of the modern insurance, however, the ocean marine insurance industry reveals numerous quite distinctive natures. Dierdre Littlefield, chairman of American Institute of Marine Underwriters (AIMU), utilized the words, "a unique animal", to portray the special characteristics of the ocean marine insurance industry. ${ }^{1}$ Differences in the way the ocean marine market performs compared with the rest of the property/ casualty market can be attributed to differences in the nature of the coverage, its exposure and how it is regulated. Firstly, ocean marine involving the movement of goods internationally is very dynamic which is very different from a static risk, like a building in the property area. Secondly, ocean marine is less regulated than property/casualty business in U.S. insurance market. Federal and state laws in the United States tend to be general in nature. This reflects the necessity for flexibility in the writing of ocean marine coverages. In particular, all states exempt ocean marine insurance

\footnotetext{
1 "The Ocean Marine Market: An Unique Animal", cover story, Insurance Journal: February 25, 2002.
} 
from any rate or form filing requirements. Thirdly, the independent agents and brokers play a dominated role in marketing system in U.S. marine insurance industry. A large number of insurers may belong to a group (i.e. syndicate) for the purpose of developing policy forms and clauses. However, there is no rating bureau in the ocean marine field comparable to the insurance rating bureaus that establish rates and policy forms for insurance coverage on land. Finally, another major difference of ocean marine is that the coverage involves cargoes or vessels that are making ports of call throughout the world, and hence, it involves different cultures, different infrastructures and different laws. In summary, therefore, the subject of pricing for ocean marine insurance is quite a complex one for actuarial professions. Originally, this paper contains an empirical investigation of underwriting cycle in U.S. ocean marine insurance market to explore the determination of the underwriting margins of ocean marine insurance, which is the crucial component of the insurance price to deal with maritime contingencies beyond insurer's expectation. Underwriting cycle, which means that underwriting margins will shift dynamically between hard and soft markets back and forth, is a common feature in property/liability insurance markets for nearly a century. How come such wide and puzzling phenomenon takes place and whether the cycle continue to portray insurance markets leaves questions that still need comprehensive explanation, especially for the ocean marine insurance. For years ocean marine insurers have recognized that the business has its good times and its bad times. In soft market periods, underwriting margins are lower and coverage is readily available to buyers, while underwriting margins are higher and insurance are more difficult to obtain in hard market periods. Underwriting cycles are a means of maintaining long-term profits, not a random occurrence that could remove them. If such fluctuations could be modeling and predicted well, insurers could dampened their volatility of operations and insurers' costs of raising capital would be reduced.

Numbers of competing theory have been advanced to account for the underwriting cycle in property/liability insurance industry [11]. Under the financial pricing hypothesis (i.e. Rational Explanations/Institutional Intervention hypothesis), insurers have rational expectations for discounted claims costs and there will be no discernable cycles in prices as well as profits should vary inversely with interest rates. The presence of underwriting cycles is instead caused by a filtration of rational expectations through special insurance market features such as patterns of claim payments, ratemaking procedures, natural catastrophes, regulatory characteristics and accounting lags. It implicates underwriting margin follows an autoregressive process which leads to underwriting cycle. Cummins and Outreville [3] utilized an AR(2) model with deterministic trend to the data and conclude such hypothesis is enough to create underwriting cycle. Several following studies also provided consistent results [5,15]. Implicitly, such model assumes insurers are risk neutral and insurance markets are perfect and efficient, thus, insurers can adjust their capital quickly enough to produce a negligible level of insolvency risk. Ac-cordingly, the underwriting margin would be a decreasing function only depended on interest rate in both the short and the longrun.

Alternatively, the well-known capacity constraint hypothesis argues that the underwriting cycle is attributable to market imperfections $[6,7,20,21]$. Uncertainty and asymmetric information in the insurance market prevent insurers from quickly adjusting their capital to the long-term equilibrium condition. Because of the imperfections of capital market, raising insurance price becomes a commonly used method to adjust capital after the insurer experiences a negative shock or unexpected crisis. These features imply that insurance price will depend on capacity or surplus inversely in the short-run; however, insurance price do not depend on surplus or capacity in the long-run. Such model is a model of short-run price determination, which the underwriting margins are decreasing with capacity. Meanwhile, the model adopt a present value notion of insurance price implicitly, thus financial pricing hypothesis still holds in both short-run and long-run [6] and the testable implication is that whether capacity negatively relate to the underwriting margins in the short-run. In addition, the financial quality hypothesis extends the capacity constraint hypothesis by taking into account the endogenous insolvency risk in insurance price [10]. Such model assumes that the shock to surplus shifts both demand and supply and the effect of supply shift is greater than demand shift in the shortrun. Therefore, the short-run implications of the financial quality hypothesis are the same with the capacity constraint hypothesis. In the long-run, underwriting margins should depend positively on the level of capacity since higher level of capacity imply higher levels of financial quality and consumers presumably have a greater willingness to pay for higher quality policies.

In contrast, Sommer [18] provided an option pricing approach to insurance pricing which the policy holders have a short position in a put option on the asset of insurers. Such put option is referred to as the insolvency put option. The lower the insurer's capacity, the greater the insolvency risk as well as the value of the insolvency put. Like the value of risky corporate debt, the value of insurance policies should be negatively correlated with the level of insolvency risk. It follows 
that the underwriting margins is increasing with insurer's capacity both in long-run and short-run and is decreasing with the interest rate as the same as the financial pricing hypothesis implies.

Adapting the framework developed by Choi et al. [2], different implications of alternative hypotheses for underwriting margins are summarized in Table 1.

Earlier empirical analyses over last decade have focused on whether the insurers' lagged surplus (i.e. capacity) is a determinant of underwriting margins. However, they concluded somewhat inconsistent evidence and still left some ambiguous interpretations. According to Venezian [19], different insurance lines may implicate different natures on underwriting margin dynamics. Very few researches, however, conducted specific by-line analysis on determinants of the underwriting margins, especially for ocean marine insurance line. Most of relevant studies focused on industry-wide level. For example, utilized a conventional regression, Cummins and Danzon [4] found that underwriting margins are positively corresponding to the lagged capacity measure, a relationship unexplainable under the capacity constraint framework. It argued that such positive relationship could be explained by the shock effect on insurance demand. An increase of capital, which reduces insurers' insolvency risk, increases insurance price, while supports the financial quality hypothesis. Higgins and Thistle [13] employed the logistic smooth transition regression to test for a regime shift and to estimate the speed of the transition between regimes. The results showed that capacity is an important determinant of underwriting margins in the short-run. However, such results are not consistent with the capacity constraint hypothesis or the financial quality hypothesis. They also found that interest rate is not a significant determinant of underwriting margins, thus implied that there are no models supportive for existing hypothesis and merit further investigation.

Most studies utilized a regression procedure which the changes of interest rate and capacity proxies have been used extensively in examining relation between levels of underwriting margins to characterize the va- lidity of capacity constraint model. Such empirical model is inherent danger and could lead to spurious regression due to misspecification [19]. For more robust and effective empirical methods in testing insurance pricing models, a growing literature analyzes determinants of insurance prices employing time series approach or econometric techniques on insurer underwriting margins. Based on pre-tests for a unit root, some studies have used cointegration analysis to analyze the long run relationship between underwriting margins and the insurance capacity proxy to test theories of the determinants of underwriting cycles. They argued that underwriting margins and other variables are not stationary which implicate that the earlier conventional regression approach is not appropriate to analyze determinants of underwriting margins. Haley [8] pointed out that the industry-wide underwriting margins and short-term interest are cointegrated with a negative long-run relationship. Haley [9] further conducted a by-line analysis to find that underwriting margin of ocean marine insurance has no unit root (means that the series is $\mathrm{I}(0)$ )which implies that the cointegration analysis is not appropriate for the underwriting margin of ocean marine insurance. Choi et al. [2] reported that insurance price is $\mathrm{I}(0)$ but interest rate and surplus series are I(1). It implicates that insurance price could not be cointegrated with neither interest rate nor surplus. Harrington and $\mathrm{Yu}$ [12] applied GLS ADF tests under $\mathrm{AR}(2)$ data generating process (DGP)to prove that underwriting margins is stationary implying that there is no need to utilize cointegration analysis in underwriting margins issue and conventional regression methods can be used appropriately to analyze underwriting margins after controlling for deterministic influences and transforming any non-stationary regressors. Their results may have some problems. First, they assumed that the underlying DGP follows an AR (2) process, which may not be an appropriate DGP in underwriting margins [16]. Second, given that problems arising from nonstationarity and autocorrelation in levels of regressors could possibly be avoided by the use of taking difference, however, any transforming or taking difference on the

Table 1. Summery of implications of underwriting margins for alternative hypotheses

\begin{tabular}{lccc}
\hline & \multicolumn{2}{c}{ Interest rate } & Capacity \\
\cline { 2 - 4 } Hypothesis & Short-run & Long-run & Short-run \\
\hline Financial pricing hypothesis & - & - & $\mathrm{x}$ \\
Capacity constraint hypothesis & - & - & $\mathrm{x}$ \\
Financial quality hypothesis & - & - & - \\
Option pricing approach & - & - & + \\
\hline
\end{tabular}

a: Symbols of -, + and $\mathrm{x}$ indicate negative impact, positive impact and no specific impact, respectively, on underwriting margin. 
variables may ignore or destroy the systematical characteristics of multiple time series. For example, if one of the variables is fractionally integrated, simply differencing may result in correlated error terms, thus may conclude unclear answers.

A critical issue in time series regression analyses is whether underwriting margins and relevant explanatory variables are stationary. Least squares regression provides meaningful inferences only when the regressand and regressors are either all stationary or cointegrated. As mention above, previous studies seem to leave the characteristic of underwriting margins ambiguous as well as the capacity proxy. It may imply that efforts have to put into the development of a more robust empirical model since some of the variables in questions are stationary while others are non-stationary. To solve this problem, ARDL (Autoregressive Distributed Lag) approach is employed to assess the long-run and short-run effects of such empirical models all together. ARDL approach can also remove problems associated with omitted variables and autocorrelation. Besides, this approach is adequate to deal with small sample problem. Since most insurance data are annual data with relatively small sample size, ARDL is an appropriate technique in examining our subject on 'Ocean Marine Insurance.' The remainder of this paper is organized as follows.

The following section briefly describes the data assessment and presents ARDL methodology. The subsequent section presents results of our analysis. The last section summarizes and concludes the study.

\section{DATA}

The objective of this paper is to construct an empirical model exploring the determinants of the underwriting margins of ocean marine insurance. Underwriting margins usually refer to insurers' underwriting returns, which is the profit margins without including investment returns. Several proxies are employed in earlier literatures. In this paper, one minus loss ratio is utilized to avoid the problem controlling for acquisition expenses [7]. The loss ratio is the ratio of losses and loss adjustment expenses incurred to net premiums earned in a calendar year. We apply annual U.S. insurance industry-wide data for ocean marine insurance during the period 1951-2001 obtained from Best's Aggregates and Averages published by A.M. Best Company (See Figure 1). The results here may facilitate comparing the results from Haley [9]. On the other hand, capacity generally refers to the degree of aggregate industry to supply insurance without increasing the level of insolvency risk. This paper considers two capacity measures that are traditionally used as industry measures of capacity. One is the lagged policyholders' surplus to lagged asset (SA) while the other is the lagged aggregate policyholders' surplus to lagged net written premiums (SP). The reason to emphasize the proxy using net written premiums is that it is the inverse of the Kennedy Ratio, which is an important financial indicator used by insurance regulators for solvency surveillance. The lagged policyholders' surplus, which reflects insurers' capacity at the beginning of a new business year, is reported at the end of previous year from Best's Aggregates and Averages. The rationale to use these two proxies is that both total liabilities and premiums should reflect insurers' future claim payments, thus may serve a better role for capacity. Finally, three-monthly Treasury bill rates collected from the Federal Reserve Bulletin are used as the proxy for short-term interest rate.

\section{METHODOLOGY}

To examine the long-run relationship between ocean marine insurance underwriting margins and its determinants, we employ the newly developed autoregressive distributed lag (ARDL) cointegration framework [17]. The method avoids the classification of variables as $\mathrm{I}(1)$ and $\mathrm{I}(0)$ by developing bands of critical values which identifies the variables as being stationary or non-stationary processes. Unlike other cointegration techniques (e.g., Johansen's procedure) which require

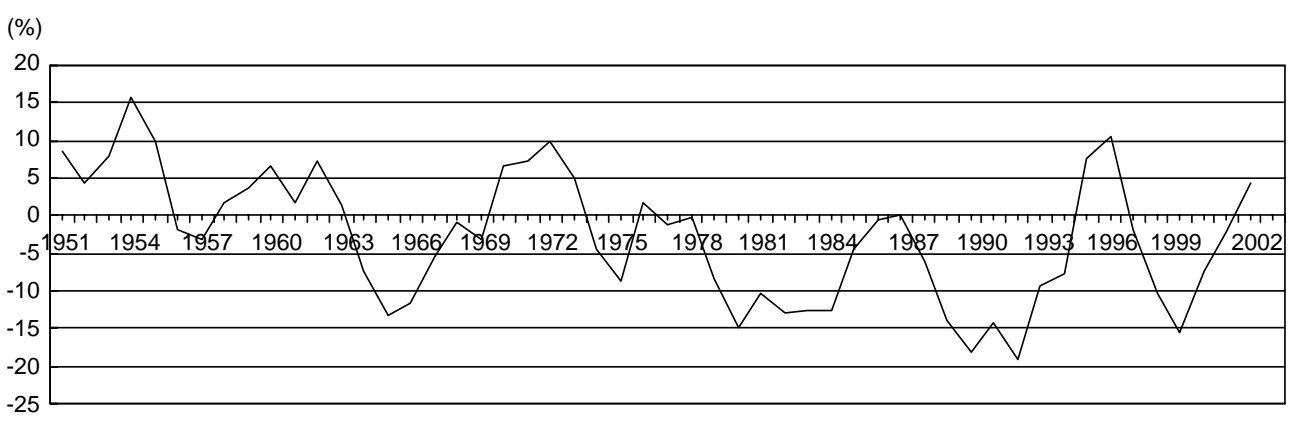

Fig. 1. Underwriting margins of ocean marine insurance. 
certain pre-testing for unit roots and that the underlying variables to be integrated of order one, the ARDL model provides an alternative test for examining a long-run relationship regardless of whether the underlying variables are purely $\mathrm{I}(0)$ or $\mathrm{I}(1)$, even fractionally integrated. Therefore, previous unit root testing of the variables is unnecessary $[9,12]$. Moreover, traditional cointegration method may also suffer from problems of endogeneity while the ARDL method can distinguish dependent and explanatory variables. Thus, estimates obtained from the ARDL method of cointegration analysis are unbiased and efficient, since they avoid the problems that may arise in the presence serial correlation and endogeneity. Note also that the ARDL procedure allows for uneven lag orders, while the Johansen's VECM does not [14].

This approach involves two stages. In the first stage, testing the null hypothesis of the non-existence of the long-run relationship is given by:

$$
\begin{aligned}
& \Delta U M_{t}=\alpha+\beta_{0} t+\sum_{i=0}^{n} \beta_{i} \Delta U M_{t-i}+\sum_{i=0}^{n} \gamma_{i} \Delta r_{t-i} \\
& +\theta_{1} U M_{t-1}+\theta_{2} r_{t-1}+\theta_{3} K_{t-1}+\varepsilon_{t} \\
& H_{0}: \theta_{1}=\theta_{2}=\theta_{3}=0 \\
& H_{1}: \theta_{1} \neq \theta_{2} \neq \theta_{3} \neq 0
\end{aligned}
$$

Where $U M, r$ and $K$ denotes underwriting margins, short-term interest rate and capacity proxy, respectively, and the number is the maximum lags on the first differenced variables. Accordingly, the relevant statistic to test (2) is the F-test or the Wald-test. Such test is used to examine the existence of a stable and long-run relationship. Note that the asymptotic distributions of the F-statistic are non-standard irrespective of whether the variables are $\mathrm{I}(0)$ or $\mathrm{I}(1)$. Since the asymptotic distribution of these two tests is non-standard, Pesaran et al. [17] provide two sets of asymptotic critical values. One set assumes all variables are $\mathrm{I}(0)$ and the other assumes that all variables are I(1). If the computed Fstatistic falls above upper limit of the bound critical value, then the null hypothesis is rejected which means the variables are cointegrated. Conversely, if the computed F-statistic falls below the lower bound critical value, then the variables are not cointegrated and the null hypothesis cannot be rejected. Finally, the case within the band would be inconclusive. Once cointegration is determined, the augmented ARDL ( $m$, $p, q)$ model is estimated using the following form:

$$
a(L, m) U M_{t}=a_{0}+b_{0} t+\sum_{i=0}^{p} c_{i} r_{t-i}+\sum_{i=0}^{q} d_{i} K_{t-i}+u_{t}
$$

where $a(L, m)=1-a_{1} L^{1}-\cdots-a_{m} L^{m}$

$L$, a lag operator such that $L^{j} U M_{t}=U M_{t-j}$

Again the maximum of lags ( $n$ ) in Eq. (1) must retain to determine the numbers of lags $(m, p, q)$ in Eq. (3) selected by the Akaike Information Criterion (AIC) or Schwartz Bayesian Criterion (SBC) to determine the optimal structure for the ARDL specification. Notices that if the underwriting margin follows second-order autoregressive model (i.e. $m=2$ ), the condition of cyclical phenomenon is the inequality as follows:

$$
a_{1}^{2}+4 a_{2}<0
$$

Having found associated ARDL model, the second stage involves estimating the long-run coefficients of underwriting margins and the associated ARDL error correction models. Incorporating the long-run and shortrun terms into the model allows a more efficient estimate of the short-run coefficients. The conditional long-run model for underwriting margins can be obtained from the reduced form solution of Eq. (3) as follows:

$$
\begin{aligned}
& U M_{t}=\lambda a_{0}+\lambda b_{0} t+\lambda \sum_{i=0}^{p} c_{i} r_{t}+\lambda \sum_{i=0}^{q} d_{i} K_{t}+\lambda u_{t} \\
& \text { where } \lambda=\frac{1}{a(L, m)}
\end{aligned}
$$

Meanwhile, the error correction (EC) representation of the ARDL model, which involves the ECM term, can be estimated by rearranging the original equation by OLS. Under ARDL approach, the existence of a unique valid long run relationship among variables, and hence a sole error-correction term, is the basis for estimation and inference. Short-run, or difference-based, relationship cannot be supported unless a unique and stable equilibrium relationship holds in significant statistical sense. According to Pesaran et al. [17], ECM estimation is significant according to a non-standard t-statistic table of critical values, which are much higher than the standard ones. Importantly, if the coefficients of the ECM term carry the expected negative sign and are highly significant, the cyclical phenomenon will be specified and will facilitate our empirical finding of cointegration as provided. The error-correction mechanism is described as follows:

$$
\begin{aligned}
\Delta U M_{t} & =\Delta \hat{a}_{0}+\hat{b}_{0} \Delta t-\sum_{j=2}^{m} \hat{a}_{j} \Delta U M_{t-j+1}+\hat{c}_{0} \Delta r_{t} \\
& -\sum_{i=2}^{p} \hat{c}_{i} \Delta r_{t-i+1}+\hat{d}_{0} \Delta K_{t}-\sum_{i=2}^{q} \hat{d}_{i} \Delta K_{t-i+1} \\
& -a(L, m) E C M_{t-1}+\varepsilon_{t}
\end{aligned}
$$


where $E C M_{t-1}=U M_{t-1}-\lambda \hat{a}_{0}-\lambda \hat{b}_{0}(t-1)-\lambda \sum_{i=0}^{p} \hat{c}_{i} r_{t-1}$ $-\lambda \sum_{i=0}^{q} \hat{d}_{i} K_{t-1}$

Notice that $\hat{a}_{j}, \hat{b}_{0}, \hat{c}_{i}$, and $\hat{d}_{i}$ are the coefficients estimated from Eq. (3), and the coefficient of the ECM term, , measures the speed of adjustment to the long-run equilibrium.

\section{EMPIRICAL RESULTS}

In testing the null of no cointegration in Eq. (1), the critical issue is choosing the maximum lag $(n)$. Bahmani-Oskooee and Boh1 [1] have shown that the results of this first stage are usually sensitive to the order of VAR. Earlier academic literatures obviously ignored such potential serious problems. In this study, we impose order of lag from 1 to 2 on the first difference of each variable and compute the F-statistic for the joint significance testing (2) of a non-standard F distribution [17]. The results are reported in Table 2. The null hypothesis of the nonexistence of the long-run relation-

Table 2. F-Statistics for testing the existence of cointegration

\begin{tabular}{ccc}
\hline \multirow{2}{*}{ Order of lag } & \multicolumn{2}{c}{ F-statistics } \\
\cline { 2 - 3 } & Capacity proxy: SP & Capacity proxy: SA \\
\hline 1 & 4.74 & 5.06 \\
2 & $5.94^{*}$ & $6.24^{*}$
\end{tabular}

a. The relevant critical value bounds are given in [17] p. 301, Table CI (v). case V (with an unrestricted intercept and unrestricted trend; $k=2$ ). They are 4.86-5.85 at the $95 \%$ significance level b. *Denotes that the F-statistic falls above the $95 \%$ upper bound. ship is rejected for both all lines combined and other liability underwriting margins when order of lag larger than one. The results provide evidence for the existence of a long-run underwriting margins equation, particularly when a higher order of lag is selected for formulating the model. Therefore, merely considering shortterm determination has not enough to explain the dynamics of underwriting margins. In the second stage, the maximum order of lag $(n=2)$ is selected in this study. Retaining the maximum lag, meanwhile, Akaike Information Criterion (AIC) and Schwartz Bayesian Criterion (SBC) are used to estimate Eq. (3). Coincidentally, both AIC and SBC selecting criterion under two different capacity proxies are formulating the same structure of ARDL $(2,0,0)$ model. The results are reported in Table 3.

As expected, such modeling framework provides well efficient estimates of parameters and all the diagnostic testing are statistically insignificant implying no evidence of misspecification. The adjusted- $R^{2}$ are approximately 60 percents for both models and the computed F-statistics clearly reject the null hypothesis that all regressors have zero coefficients for all cases, suggesting that such ARDL models fit the data reasonably well. In particular, the CUSUM test for examining the stability of the model shows that the cumulative sum of residuals are within the critical bands, indeed they follow a central path indicating a high level of parameter stability (see Figure 2). Similarly, the CUSUM of squares test reveal that the plot of the cumulative sum of squares of recursive residuals goes through the centre of the critical bands (see Figure 3). These results suggest the model's parameters are stable over the sample period.

Estimating of dynamic relationships between ocean marine insurance underwriting margins and other vari-

Table 3. Estimates of ARDL model for ocean marine underwriting margins

\begin{tabular}{ccc}
\hline \multirow{2}{*}{ Coefficient } & Capacity proxy: SP & Capacity proxy: SA \\
\cline { 2 - 3 } & ARDL $(2,0,0)$ & ARDL $(2,0,0)$ \\
\hline Constant & $8.14(.072)^{*}$ & $11.69(.173)$ \\
$t$ & $-.03(.621)$ & $-.11(.133)$ \\
$U M_{t-1}$ & $.81(.000)^{* *}$ & $.83(.000)^{* *}$ \\
$U M_{t-2}$ & $-.35(.017)^{* *}$ & $-.36(.011)^{* *}$ \\
$r_{t}$ & $-.91(.024)^{* *}$ & $-.82(.026)^{* *}$ \\
$K_{t}$ & $-4.52(.286)$ & $-16.80(.350)$ \\
Adj. $R^{2}$ & .60 & .60 \\
F-stat. & $15.69(.000)^{* *}$ & $15.54(.000)^{* *}$ \\
DW-statistic & 2.16 & 2.17 \\
LM Serial correlation F test & $2.37(.130)$ & $2.74(.105)$ \\
Heteroscedasticity F test & $.07(.782)$ & $.01(.910)$ \\
RESET F test & $.65(.424)$ & $.27(.605)$ \\
\hline
\end{tabular}

a. Observations 1951-2001

b. ( ) denotes probability values;

c. $*$ significant at the $90 \%$ significance level; $* *$ significant at the $95 \%$ significance level. 
ables requires an estimation method designed to deal with the particular problems raised by the inclusion of lagged dependent variables. After controlling the variables of interest rate and capacity proxy, the underwriting margins for ocean marine insurance seem to follow AR(2) process at $95 \%$ significant level. This result demonstrates that the first lagged and the second lagged underwriting margins, which reveal opposite signs, have crucial explanatory power on the current period underwriting margin. Unlike prices for commodities and shares of stock, the prices of insurance policies cannot be changed simultaneously to reflect new information. Under financial pricing hypothesis advocated by Cummins and Outreville [3], the effect of information lags can produce an AR(1) model and the combined effects of reporting lags and information lags can gen- erate an underwriting cycle, thus $\mathrm{AR}(2)$ process with deterministic trend yields a good data generating process. Many following research adopted the same assumption [12, 15], however, Leng and Venezian [16] argued such predetermined model may involve serious errors in specification and not valid for modeling underwriting margins. In contrast, our result with carefully data assessing provides a more reliable explanation with statistically recognizing. Moreover, the coefficients of the first lagged and the second lagged underwriting margin are satisfied with the Inequality (4), which provides an empirical proof for the existence of underwriting cycle. For the variable of interest rate, both models confirm the negative relationships between the underwriting margins and current interest rate. Such findings are consistency with implications of financial
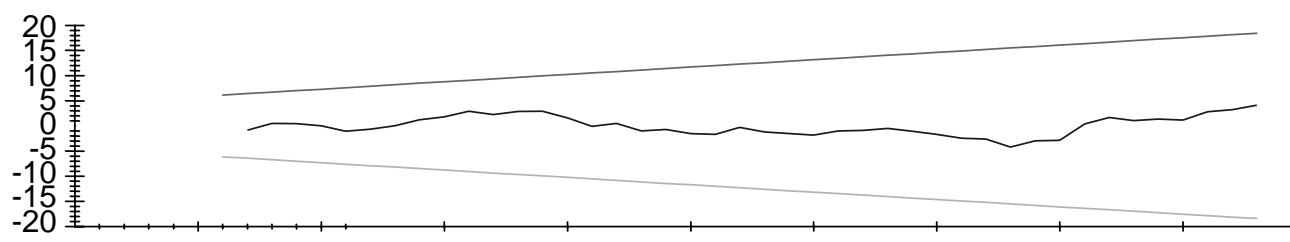

Capacity proxy: SP

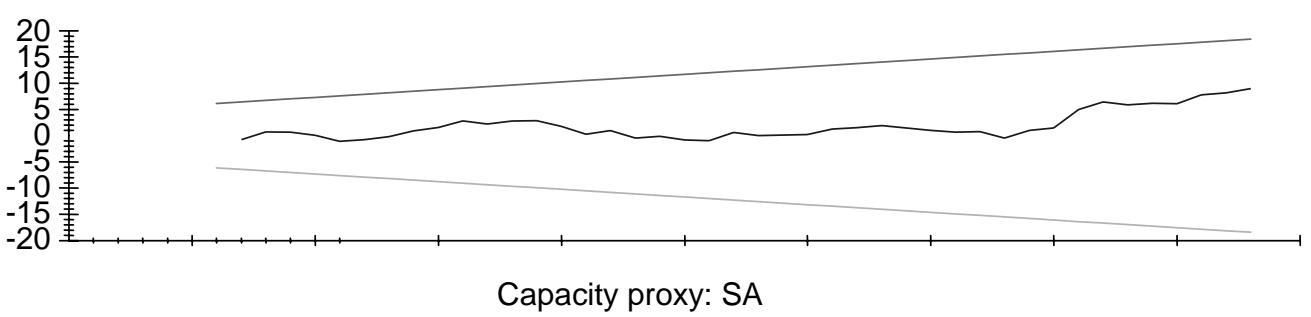

Fig. 2. Plot of cumulative sum of recursive residuals.

Note: The straight lines represent critical bounds at $5 \%$ significance level

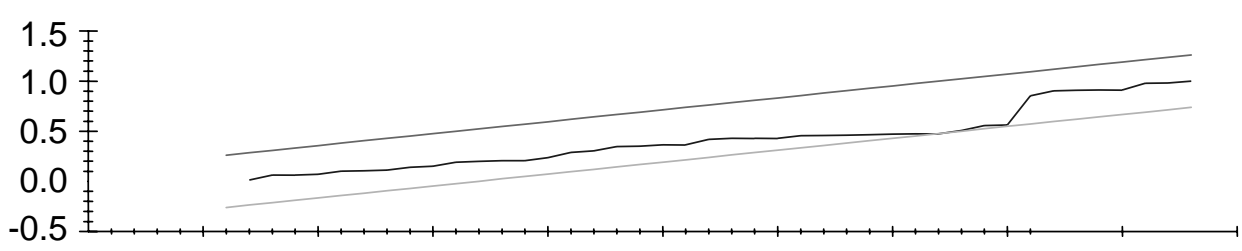

Capacity proxy: SP

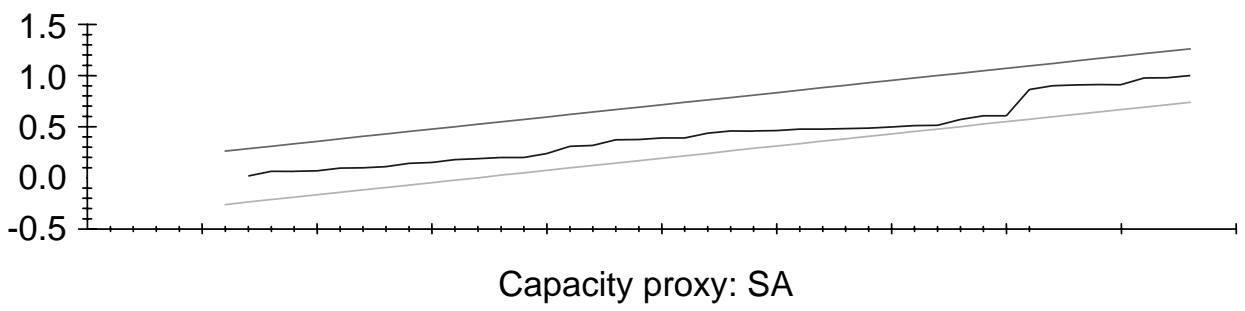

Fig. 3. Plot of cumulative sum of squares of recursive residuals.

Note: The straight lines represent critical bounds at $5 \%$ significance level 
pricing hypothesis. Furthermore, there is worthy to note that the coefficient of the capacity proxy is substantially negligible which against the implication of the popularly receivable capacity constraint hypothesis. After estimating the associated ARDL model, it would be necessary to separate the long-run and short-run implications. The static long-run model and the error correction representation of the corresponding ARDL model are reported in Tables 4 and 5.

As shown in Table 4, the static long-run model shows interest rate is cointegrated with underwriting margins, which means that there exists an economic equilibrium between interest rate and underwriting margin. Our methodology avoids Haley's problem [9], which concluded that the cointegration analysis is not allowed to utilize for the ocean marine insurance due to the previous limited unit root testing procedure. Besides, following ECM reference shown in Table 5 reinforces our findings of equilibrium as well as the underwriting cycle dynamics. The error correction coefficient reveals a highly significant negative sign in both models and the interest rate is the only significant variable in the short-run. Combining the findings of long-run model and ECM reference, the financial pricing hypothesis would be the only suitable theory to explain dynamics of U.S. ocean marine insurance market, and hence, the optimal structure of model has confirmed to be AR (2). Such second-order autoregressive model could be due to the characteristic of long claims tail for ocean marine insurance. The" tail" means the time between the accident event and actual payment. As mention above, the second order autoregressive process is consequent to reporting lags, which usually emerges in long tail lines. In ocean marine insurance industry, long claims tail and reporting lags are the most common features. Furthermore, the interest rate reveals a negative direction to underwriting margins in both long-run and short-run as we expected. Interestingly, for capac-

Table 4. Estimated long run effects of ARDL model

(Dependent Variable: Ocean Marine Underwriting Margins)

\begin{tabular}{ccc}
\hline \multirow{2}{*}{ Coefficient } & Capacity proxy: SP & Capacity proxy: SA \\
\cline { 2 - 3 } & ARDL $(2,0,0)$ & ARDL $(2,0,0)$ \\
\hline Constant & $15.22(8.5962)^{*}$ & $16.68(16.6815)$ \\
$t$ & $-.07(.13442)$ & $-.21(.13320)$ \\
$r_{t}$ & $-1.70(.78149)^{* *}$ & $-1.55(.13320)^{* *}$ \\
$K_{t}$ & $-8.45(8.2362)$ & $-31.50(34.9925)$ \\
\hline
\end{tabular}

a. Observations 1951-2001

b. ( ) denotes standard deviation.

c. Significant at the $90 \%$ significance level; ** significant at the $95 \%$ significance level.

Table 5. Error correction representation of ARDL model

(Dependent Variable: First Difference of Ocean Marine Underwriting Margins)

\begin{tabular}{ccc}
\hline \multirow{2}{*}{ Coefficient } & Capacity proxy: SP & Capacity proxy: SA \\
\cline { 2 - 3 } & ARDL $(2,0,0)$ & ARDL $(2,0,0)$ \\
\hline Constant & $8.14(4.4163)^{*}$ & $11.69(8.4362)$ \\
$\Delta_{t}$ & $-.03(.075316)$ & $-.11(.075415)$ \\
$E C M_{t-1}$ & $-.53(.11716)^{* *}$ & $-.53(.11793)^{* *}$ \\
$\Delta U M_{t-1}$ & $.35(.14244)^{* *}$ & $.36(.13964)^{* *}$ \\
$\Delta r_{t}$ & $-.91(.38886)^{* *}$ & $-.82(.35904)^{* *}$ \\
$\Delta K_{t}$ & $-4.52(4.1889)$ & $-16.80(17.8003)$ \\
\hline
\end{tabular}

a. Observations 1951-2001

b. ( ) Denotes standard deviation.

c. The relevant critical value bounds (non-standard t-statistics) for ECM term reference are given in p. 304, Table CII (v).case V (with an unrestricted intercept and unrestricted trend; $k=2)$, Pesaran et al. (2001). They are (-3.41, -3.95) at the 95\% significance level, $(-3.13$, $-3.63)$ at the $90 \%$ significance level.

d. * significant at the $90 \%$ significance level; ** significant at the $95 \%$ significance level. 
ity proxy, models show apparent insignificant both in long-run and short-run relationship which denied the models involving capacity implication. Only financial pricing hypothesis provides a definitive construction of ocean marine insurance. Unlike other hypotheses, which have assumed that insurance profits were determined primarily by supply-side considerations, financial pricing hypothesis hypothesize that prices and profits are established in a rational, competitive market. Prices are rational in the sense that they accurately reflect the expected value of losses, conditional upon all information available at the time rates are set. Both demand and supply play a role in the determination of insurance price, therefore, the insurance markets are competitive so that no monopoly rents exist. In the United States, as mention in introduction, ocean marine insurance industry includes insurance companies, underwriting managers, brokers and agents, and various other organizations and professions that meet special needs. A large portion of the ocean marine business is placed through brokerage offices specializing in this kind of business. Marine insurance brokers are more than sales and service representative but are risk management consultants who have responsible for insurance arrangement, designing customized products, even a risk controllor for insured. If the insurance companies raise insurance prices much higher, brokers may adivse their customers to adopt risk control, self insurance, capative insurance or other alternative risk management techniques. The existence of numurous brokers and agents enhances bargaining power of customers and advances the marine insurance markets become more competitive. On the other hand, due to the existence of mature global reinsurance markets for marine insurance (e.g., Lloyd's of London), the capacity consideration may not be substantial issues for insurance companies in the United States. If insurance companies raise their underwriting margins indiscreetly when the capacity is deficient, they might lose their market shares. Our results validate such unique characteristics of ocean marine insurance markets.

\section{CONCLUSION REMARK}

The major contribution of this study employing ARDL framework is to originally investigate the presence and causes of the underwriting margins dynamics in U.S. ocean marine insurance market and to criticize the previous ambiguous findings which their models utilizing conventional regression or traditional cointegression inherent left to misspecification. Our study reveals several interesting findings. First, the second-order autoregressive model supports the existence of its unique long-tail-claim characteristic which aggravates the combined effects of information lags and reporting lags. Second, besides the two lags of itself, current underwriting margin is only influenced by interest rate that validate the financial pricing hypothesis [3], which implicates the existence of competitive market. Capacity, however, is not a determinant of underwriting margin in ocean marine insurance market. The rationale for competitive market may attribute to several unique features of ocean marine insurance market including less regulation due to its universal nature, enhancing bargaining power due to numurous brokers, utilizing alternative risk management technique, and the existence of mature global reinsurance markets. As compared with other insurance lines in U.S. market, our findings conclude that the long-historic U.S. ocean marine insurance market is a mature, efficient, and competitive insurance line. Such results may be extended to other insurance lines in U.S. or world insurance markets for further study.

\section{REFERENCES}

1. Bahmani-Oskooee, M. and Bohl, M.T., "German Monetary Unification and the Stability of the German M3 Money Demand Function," Economics Letters, Vol. 66, pp. 203-208 (2000).

2. Choi, S., Hardigree, D., and Thistle, P.D., "The Property-Casualty Insurance Cycle: a Comparison of Alternative Models," Southern Economic Journal, Vol. 68, pp. 530-548 (2002).

3. Cummins, J.D. and Outreville, J.F., “An International Analysis of Underwriting Cycles in the Property-Liability Insurance," Journal of Risk and Insuranc, Vol. 54, pp. 246-262 (1987).

4. Cummins, J.D. and Danzon, P.M., "Price, Financial Quality and Capital Flows in Insurance Markets," Journal of Financial Intermediation, Vol. 6, pp. 3-38 (1997).

5. Doherty, N.A. and Kang, H.B., "Interest Rates and the Insurance Price Cycle," Journal of Banking and Finance, Vol. 12, pp. 199-215 (1988).

6. Doherty, N.A. and Garven, J.R., "Insurance Cycles: Interest Rates and the Capacity Constraint Hypothesis," Journal of Business, Vol. 68, pp. 383-404 (1995).

7. Gron, A., "Capacity Constraints and Cycles in Property-Casualty Insurance Markets," Rand Journal of Economics, Vol. 25, pp. 110-127 (1994).

8. Haley, J., "A Cotintegration Analysis of the Relationship Between Underwriting Margins and Interest Rates: 1930-1989," Journal of Risk and Insurance, Vol. 60, pp. 480-493 (1993).

9. Haley, J., "A By-Line Cointegration Analysis of Underwriting Margins and Interest Rates in the PropertyLiability Insurance Industry," Journal of Risk and Insurance, Vol. 62, pp. 755-763 (1995). 
10. Harrington, S.E. and Danzon, P.M., "Price Cutting in Liability Insurance Markets," Journal of Business, Vol. 67, pp. 511-538 (1994).

11. Harrington, S.E. and Niehaus, G., Volatility and Underwriting Cycle, in Geoges Dionne,ed., The Handbook of Insurance Economics, Kluwer Acadamic, Boston (2000).

12. Harrington, S.E. and Yu, T., "Do Property and Liability Insurance Underwriting Margins Have Unit Roots?" Journal of Risk and Insurance, Vol. 70, pp. 735-753 (2003).

13. Higgins, M. and Thistle, P., "Capacity Constraints and the Dynamics of Underwriting Profits," Economic Inquiry, Vol. 38, pp. $442-457$ (2000).

14. Johansen, S., "Statistical Analysis of Cointegration Vectors and Dynamics and Control," Journal of Econometrics, Vol. 12, pp. 231-254 (1988).

15. Lamm-Tennant, J. and Weiss, M.A., "International Insurance Cycles: Rational Expectations/Institutional Intervention," Journal of Risk and Insurance, Vol. 64, pp. 415-439 (1997).
16. Leng, C.C. and Venezian, E., "Underwriting Profits: Are the Data Consistent with "Rationally Priced" Insurance Cycles?” Assurances et Gestion des Risques, Vol. 71, pp. 435-454 (2003).

17. Pesaran, M.H., Shin, Y., and Smith, R.J., "Bounds Testing Approaches to the Analysis of Long-Run Relationship," Journal of Applied Econometric, Vol. 16, pp. 289-326 (2001).

18. Sommer, D.W., "The Impact of Firm Risk on PropertyLiability Insurance Prices," Journal of Risk and Insurance, Vol. 63, pp. 501-514 (1996).

19. Venezian, E.C., "Empirical Analysis on the Underwriting Cycle: An Evaluation," Assurances et Gestion des Risques, Vol. 70: 295-314 (2002).

20. Winter, R.A., "The Liability Crisis and The Dynamics of Competitive Insurance Markets," Yale Journal on Regulation, Vol. 5, pp. 455-499 (1988).

21. Winter, R.A., "The Dynamics of Competitive Insurance Markets," Journal of Financial Intermediation, Vol. 3, pp. 379-415 (1994). 